\title{
Tratamiento antirretroviral del HIV en 1998 Resumen de las recomendaciones de la International AIDS Society-USA
}

\section{Introducción}

Durante la duodécima conferencia sobre SIDA que se desarrolló en Vancouver, Canadá durante julio de 1996, la Sociedad Internacional de SIDA (International AIDS- Society-USA, IAS-USA) presentó sus primeras recomendaciones de terapia antirretroviral. Estas recomendaciones se basaron en las drogas de aparición reciente, que utilizadas en combinación ofrecían una alternativa inexistente hasta ese momento.

Dos años han pasado desde entonces, y ésta misma sociedad ha realizado anualmente puestas al día de dichas recomendaciones.

\section{Fuentes}

El grado de evidencia utilizado por el panel de La IAS-USA se basó en la revisión de estudios clínicos, de ciencias básicas y de opiniones de expertos. Se incluyeron estudios clínicos en fase III, resultados finales clínicos, virológicos e inmunológicos; datos presentados en conferencias de investigación; y estudios de fisiopatología del HIV.

\section{Conclusiones Principales}

Se concluyó que la evidencia acumulada mediante estudios clínicos y de patogénesis continúa respaldando la institución de una terapia antirretroviral potente en los pacientes con infección por HIV. Una gran variedad de combinaciones de drogas ha demostrado su eficacia, habiendo aumentado por lo tanto las opciones terapéuticas para las personas infectadas.

La medición de la carga viral con los nuevos métodos ultrasensibles es un elemento importante para monitorear la respuesta terapéutica, aunque no se ha definido aún claramente qué nivel de carga viral debe considerarse como una falla del tratamiento. Han comenzado a ser cada vez más conocidos, los efectos adversos que aparecen luego del uso prolongado de las drogas y que requieren atención permanente.

Una de las cuestiones que quedaron sin resolver, es el manejo óptimo de la terapia antirretroviral a largo plazo.

\section{Fundamentos científicos de las presentes recomendaciones}

Los aportes fundamentales de Perelson y Ho en 1995 continúan proporcionando las bases fisiopatológicas de las presentes recomendaciones. La replicación del HIV es un proceso activo desde el día cero de la infección, con una producción promedio de 109 viriones diarios y que hace necesario el uso de una combinación de drogas antirretrovirales de alta eficacia para lograr una supresión duradera de la replicación viral.

Los cálculos iniciales evidenciaban que la dinámica del HIV mostraba dos fases de declinación frente a la terapia antirretroviral: 1) una primera fase dependiente de los linfocitos CD4 activados e infectados, que producen viriones activamente y que tienen una vida media de 1,6 días.

2) una segunda fase atribuida a las células infectadas de larga sobrevida, como los linfocitos no activados y los macrófagos, con una vida media estimada entre 14 y 28 días.

La identificación de la segunda fase de declinación llevó a la hipótesis de que estos reservorios morirían en forma natural y espontáneamente. Mediante cálculos matemáticos se llegó a la conclusión de que el HIV podía ser erradicado a lo largo de tres años de completa supresión de la replicación viral.

Datos recientes han causado una modificación en este concepto. Existe una pequeña, pero crítica cantidad de células CD4 de memoria que persisten con ADN viral integrado en su genoma, el cual puede producir virus capaz de replicarse en personas con supre- sión viral debida a terapias antirretrovirales de alta eficacia por más de dos años. La longevidad de dichas células no se conoce, pero estaría en un rango de meses a años, y su relevancia biológica es incierta.

La implicancia práctica de este concepto, es que a la luz de los conocimientos actuales (1998), el comienzo de un tratamiento antirretroviral contra el HIV implica el compromiso duradero de no suspenderlo. Esta cuestión no debe tomarse a la ligera, ya que la adherencia al tratamiento, los efectos colaterales de la medicación a largo plazo, el impacto sobre la calidad de vida, y la evolución de las cepas resistentes deben ser tomadas en cuenta con cada persona en quien se considere iniciar un tratamiento.

Estos estudios, además de dar un mensaje de precaución, proveen de evidencia positiva que avala el uso de terapias antirretrovirales de alta eficacia. A pesar del aislamiento del virus en personas que han estado con la máxima supresión de la replicación viral por más de dos años, no se han observado mutantes resistentes en estos pacientes. Debe agregarse además, que la supresión de la carga viral por debajo de los niveles de detección de los métodos ultrasensibles actuales (20-40 copias por $\mathrm{ml}$ ) se correlaciona con la durabilidad de la respuesta antiviral.

El uso de terapias combinadas potentes ha resultado en una notable disminución en las tasas de hospitalización, morbilidad y mortalidad (esto sólo ocurre cuando las drogas están disponibles). Tanto los médicos como los pacientes están enfrentándose a la aplicación clínica de principios terapéuticos que, debido a la rapidez del desarrollo del conocimiento en este área, no figuran si quiera en la literatura médica revisada por pares.

\section{Drogas antirretrovirales disponibles}

Hay doce drogas antirretrovirales aprobadas, las cuales pertenecen a tres familias distintas.:

Inhibidores nucleósidos de la transcriptasa reversa (INTR): zidovudina (AZT), didanosina o (DDI), zalcitabina (DDC), lamivudina (3TC) y stavudina (D4T).

Inhibidores no nucleósidos de la transcriptasa reversa (INNTR): nevirapina, delavirdina y efavirenz.

Inhibidores de la proteasa (IP): indinavir, saquinavir, nelfinavir y ritonavir.

Al ser un virus ARN, el HIV posee un complejo mecanismo de replicación, requiriendo de varias enzimas para este proceso. Las drogas antes mencionadas actúan inhibiendo dichos pasos metabólicos, e impidiendo de esta forma la replicación.

Tres drogas de investigación se encuentran en estadios avanzados de evaluación clínica: abacavir (INTR), amprenavir (IP) y adefovir dipovoxil (inhibidor nucleótido de la transcriptasa reversa, pero de una familia distinta de las anteriores).

La elección de los regímenes de combinaciones no es una simple reflexión de las posibles permutaciones derivadas de una lista de drogas disponibles. Las opciones disponibles se ven restringidas por consideraciones prácticas, como la compatibilidad entre las drogas, los distintos efectos adversos y la resistencia cruzada (especialmente cuando hay falla en el tratamiento o resistencia al mismo).

Las estrategias a largo plazo son esenciales para maximizar los beneficios terapéuticos: balancear la potencia, la tolerancia, la complejidad del régimen, los efectos adversos, el riesgo de resistencia y el costo.

Las presentes recomendaciones están diseñadas para asistir a la toma de decisiones sobre la base de los objetivos antes mencionados. 
¿Cuándo se comienza el tratamiento antirretroviral?

El panel de la IAS-USA continúa recomendando la terapia antirretroviral para cualquier paciente con infección por HIV establecida que presente alguna de las siguientes características:

Síntomas relacionados a su infección por HIV, independiente de sus niveles de linfocitos CD4 y carga viral.

Asintomático, con una carga viral mayor de 5000/10.000 copias/ml, y dispuesto a recibir una terapia compleja y de larga duración.

Los datos acumulativos muestran que la carga viral es un fúerte e independiente predictor de evolución clínica.

El grado y la durabilidad de la respuesta virológica se correlaciona directamente con los niveles de la carga viral y con el recuento de CD4 basales. Ambas determinaciones deben realizarse por duplicado, en visitas separadas y con los mismos métodos. Luego de las mismas se debe discutir con el paciente las opciones terapéuticas, implicancias y requerimientos.

La primera intervención terapéutica es la más importante para la obtención de la máxima y durable respuesta terapéutica, ya que la aparición de resistencia puede limitar severamente las opciones siguientes. El tratamiento no debe ser comenzado hasta que el paciente comprenda los objetivos y acepte la necesidad de una firme adherencia al mismo.

Para los pacientes asintomáticos con cargas virales bajas (menores $5000 / 10.000$ copias $/ \mathrm{ml}$ ) y un recuento de CD4 alto (mayor a $350 / 500$ células $/ \mathrm{ml}$ ), podría ser apropiado postergar el comienzo del tratamiento con un seguimiento clínico muy cercano. Esta recomendación se fundamenta en la complejidad del tratamiento, el riesgo de los efectos adversos, las consecuencias de la resistencia viral y la posibilidad de que esas personas puedan pertenecer a la categoría ampliamente descripta de no progresadores de larga data (del inglés "long-term nonprogresors").

Para aquellos con una carga viral baja (menor a 5000/10.000 copias/ml) y un recuento de CD4 también bajo (menor a 500 células/ml y particularmente aquellos con menos de 350 células/ml), se recomienda la iniciación del tratamiento. Es.ta indicacón se basa en que la disminución de los linfocitos CD4 tiene un valor pronóstico independiente y a que existen estudios clínicos que avalan dicha conducta.

\section{Regimenes antirretrovirales iniciales}

El objetivo de la terapia antirretroviral es mejorar la sobrevida y disminuir la morbilidad a través de una máxima supresión de lả replicación del HIV. La elección del régimen también tiene que tomar en consideración la preservación de las futuras opciones de tratamiento ante un eventual fracaso del esquema inicial. Un abordaje terapéutico que no suprima en forma máxima la replicación viral puede devenir en resistencia y en falla del tratamiento, limitando aún más las opciones futuras del mismo.

Las combinaciones actualmente en uso o bajo investigación para iniciar la terapia antirretroviral incluyen a las siquientes:

Un inhibidor de la proteasa y dos inhibidores de la trancriptasa reversa nucleosídicos.

Un inhibidor de la transcriptasa reversa no nucleosídico y dos inhibidores de la trancriptasa reversa nucleosídicos.

Dos inhibidores de la proteasa con o sin uno o dos inhibidores de la trancriptasa reversa nucleosídicos.

Un inhibidor de la proteasa y un inhibidor de la transcriptasa reversa no nucleosídico, con o sin uno o dos inhibidores de la trancriptasa reversa nucleosídicos.

Tres inhibidores de la trancriptasa reversa nucleosídicos.
Estos regímenes tienen un éxito virológico en un rango del $60 \%$ al $90 \%$ en pacientes vírgenes de tratamiento previo, como se demuestra por obtener una carga viral menor a $500 \mathrm{cop} / \mathrm{ml}$ a 24 semanas o más. La ausencia de datos de estudios randomizados comparativos hace imposible afirmar que un esquema es superior a otro a largo plazo.

En éste momento, la iniciación con un potente IP y 2 INTR debería permanecer como primera consideración, dado el soporte proveniente de los estudios clínicos en cuanto a la durabilidad de estas combinaciones y a los datos de estudios basados en población que documentan la disminución en la morbilidad y la mortalidad.

\section{¿Cuándo se cambia el tratamiento antirretroviral?}

Las indicaciones básicas para el cambio en la terapia son: falla de tratamiento, efectos adversos de las drogas, intolerancia y falta de adherencia, que no han cambiado con respecto a ediciones anteriores de estas recomendaciones. No obstante, existe actualmente refinamiento en los instrumentos de monitoreo, incrementando la complejidad de la definición de falla de tratamiento y nuevas consideraciones deben hacerse con respecto a modificaciones en el tratamiento en ausencia de un efecto adverso a las drogas o falla en la acción terapéutica en las mismas, así como el reconocimiento de la toxicidad de las drogas a largo plazo.

Un avance considerable para el monitoreo del tratamiento ha sido el desarrollo de métodos de detección de carga viral ultrasensibles, capaces de detectar entre $20-40 \mathrm{cop} / \mathrm{ml}$. Esta disponibilidad ha cambiado el concepto de falla de tratamiento, definida como la confirmación de una carga viral detectable, esto es $>50 \mathrm{cop} / \mathrm{ml}$ en un paciente adherente y que había experimentado una reducción anterior por debajo de este límite en determinaciones anteriores. Los estudios de dinámica viral indicarían que es muy alta la probabilidad de aparición de variantes virales resistentes si la replicación no es inhibida en forma máxima. No obstante, los miembros del panel dan una señal de prudencia en cuanto que no existe suficiente evidencia de estudios prospectivos de que los pacientes con cargas entre 50 y $500 \mathrm{cop} / \mathrm{mL}$ se beneficien de un cambio en sus esquemas de tratamiento.

La aparición de efectos adversos luego de una prolongada exposición a los tratamientos antirretrovirales no constituye una indicación mandatoria del cambio en el esquema, dependiendo de la gravedad y la naturaleza de la toxicidad. Los autores recomiendan la discusión con el paciente "previamente" a la iniciación de todo tratamiento de los posibles efectos adversos del mismo.

\section{Esquemas antirretrovirales de recambio}

Cuando la decisión está tomada, el cambio debe realizarse dependiendo de los motivos del mismo. Cuando es debido a toxicidad de las drogas, intolerancia o mala adherencia en el contexto de un régimen exitoso (esto es una carga viral menor del límite de detección), una sustitución selectiva del o los fármacos responsables, es la conducta razonable.

Cuando el cambio en el tratamiento es indicado debido a una falla en las drogas elegidas, las recomendaciones son las mismas que las que anteriormente se han descripto, esto es básicamente el reemplazo del régimen anterior por uno completamente nuevo, evitando drogas que presenten resistencia cruzada o de "clase" con las que ya previamente fue expuesto el paciente.

Dado el número creciente de combinaciones potenciales, no es posible mencionar aquí todos los regímenes alternativos para cada régimen inicial.

La pregunta más importante de 1998 es cómo manejar a los pacientes en los cuales un régimen que contiene un inhibidor de proteasa 
ha fallado. Estudios clínicos, prospectivos y randomizados se encuentran dedicados a responder esta cuestión.

La cuestión de cuando detener el tratamiento es mencionada como razonable cuando el paciente, luego de una discusión con su médico, considera que los efectos adversos de la medicación superan los beneficios potenciales de la terapia.

\section{Consideraciones especiales}

En estas recomendaciones, el tratamiento de la infección primaria por HIV, la infección por HIV durante el embarazo y la profilaxis post-exposición, es discutido en forma especial.

El inicio inmediato de una terapia antirretroviral de alta eficacia está indicado cuando un paciente es diagnosticado con una infección primaria por HIV, esto es dentro de las primeras semanas de la infección, esté o no sintomático. Datos recientes indicarían beneficio inmunológico cuando la terapia se inicia antes de la seroconversión.

El tópico de la infección por HIV durante el embarazo ha sido extensamente revisado por la Fuerza de Tareas del Servicio de Salud Pública de los EEUU. En esencia, las mujeres embarazadas deben recibir el mismo tratamiento que las personas no embarazadas. Existen, sin embargo, situaciones en que la terapia debe ser modificada. Si la infección por HIV y el embarazo son diagnosticadas simultáneamente durante el primer trimestre del embarazo, o si la mujer embarazada se encuentra en un estadio temprano de su infección por HIV, podría ser preferible diferir el comienzo del tratamiento hasta el segundo trimestre, momento en el cual una potente combinación puede ser indicada. Debido a la evidencia de estudios clínicos disponibles, la zidovudina (AZT) debe ser incluido en cualquier combinación que se elija.

Los beneficios de la profilaxis post-exposición han sido establecidos en el medio hospitalario y de laboratorio; el comienzo de terapia combinada con dos o más drogas antirretrovirales estaría indicado luego de una exposición ocupacional de alto riesgo. De acuerdo al Centro de Control de Enfermedades de Atlanta, EEUU, esta profilaxis debería mantenerse durante cuatro semanas. Basados en esta evidencia, se está explorando la posibilidad de ofrecer profilaxis post-exposición en otras áreas como la exposición de alto riesgo involuntaria sexual o con agujas, pero aún es prematuro hacer recomendaciones en este aspecto.

\section{Comentario}

Las presentes recomendaciones reflejan el rumbo que la terapia antirretroviral ha seguido desde 1996, donde la mejor comprensión de la fisiopatología de la infección, la posibilidad de medir la carga viral, sumada a la aparición de los inhibidores de la proteasa y los inhibidores no nucleósidos de la transcriptasa reversa posibilitó el diseño de lo que se ha dado en llamar la "terapia de alta eficacia". La evidencia de los estudios de mortalidad muestran cuan dramáticamente dicha tasa se ha reducido en los dos últimos años en los pacientes con SIDA que reciben tratamiento. En los pacientes asintomáticos la recomendación de tratamiento está basada en la prolongación del intervalo libre de enfermedad, ya que lo reciente de estos tratamientos hacen imposible que contemos aún con datos de mortalidad en esta población.

Dos aspectos nuevos se han agregado en esta edición 1998 de las recomendaciones de la IAS-USA, referentes a la adherencia a los tratamientos y los efectos tóxicos de las drogas a largo plazo. El termino "adherencia" se refiere a la rigurosidad con el que el paciente cumple con la medicación que se le ha indicado. Estudios presentados durante la última conferencia internacional sobre SIDA en Ginebra en julio de este año muestran las fallas de tratamiento, definidas cómo un aumento en la carga viral, son directamente proporcionales a la adherencia del paciente a la medicación indicada. Por esto en varias oportunidades se menciona la "voluntad" del paciente para adherir a complejos regímenes de tratamiento, como parte de las recomendaciones. El otro punto importante es el reconocimiento de significativos efectos adversos de las drogas que no estaban previamente descriptos. Alteraciones en el metabolismo de los lípidos, como hipertrigliceridemia y hipercolesterolemia; aumento de la resistencia a la insulina; diabetes; redistribución de la grasa corporal (lipodistrofia) y policitemia han sido publicados. Es aún controvertido atribuir al componente de inhibidores de proteasa toda la responsabilidad, ya que algunas de éstas alteraciones están también descriptas, aunque en proporciones ínfimas, en pacientes que no reciben estos tratamientos.

¿Cuál es el rol del médico de atención primaria en la atención de los pacientes con HIV/SIDA?

La evidencia publicada muestra que lo que es crítico en la mortalidad de los pacientes es la experiencia del médico y no su especialidad previa, es decir que a mayor número de pacientes, menor mortalidad. Todo médico debería conocer adecuadamente el manejo de las conductas de riesgo, pudiendo diagnosticar y realizar la adecuada consejería en los pacientes HIV positivos; el control del tratamiento debería ser dejado para aquellos con más experiencia en el tema. El complejo manejo de las personas viviendo con HIV requiere del médico dedicación de gran parte de su tiempo de estudio exclusivamente al tema, sólidos conocimientos en medicina interna y una formación humanistica, que le permitan el abordaje integral del tratamiento. Como los miembros del panel de expertos de la IAS-USA afirman, el tratamiento antirretroviral no es solamente elegir una combinación entre las drogas disponibles, implica adecuar el mejor esquema para cada persona, ya que "el mejor tratamiento, es el que el paciente es capaz de aceptar".

\section{Dr. Ricardo A. Mackintosh}

Servicio de Medicina Interna. CEMIC

\section{Referencias}

1. Carpenter CCJ, FischL MA, Hammer SM, et al. Antirretroviral therapy for HIV infection in 1996: recomendations on an international panel. JAMA. 1996; 276:146-154.

2. Ho DD, Neumann AU, Perelson AS, et al. Rapid turnover of plasma virions and CD4+ lymphocytes in HIV-1 infection. Nature. 1995: 373:123-126.

3. Perelson AS, Neumann AU, et al. HIV-1 dynamics in vivo: virion clearance rate, infected cell life-span, and viral generation time. Science. 1996; 271: 1582-1586.

4. Hogg RS, Heath KV, et al. Improved survival among HIV-1 infected individuals following initiation of antiretroviral therapy. JAMA. 1998; 279: 450-454.

5. Guidelines for the use of anteretroviral agents in HIV-infected adults and adolescents. Department of Health and Human Services and the Henry J. Kaiser Family Foundation. MMWR. 1998:

47(RR-5): 43-82.

6. Kitihata MM et al. Physician's esperience with the acquired immunodeficiency syndrome as a factor in patiens's survival. NEJM 1996; 334:701-706. 